\title{
SEBARAN SPASIAL CUMI-CUMI (Loligo Spp.) DENGAN VARIABEL SUHU PERMUKAAN LAUT DAN KLOROFIL- $a$ DATA SATELIT MODIS AQUA DI SELAT KARIMATA HINGGA LAUT JAWA
}

\author{
Budhi Agung Prasetyo, Sahala Hutabarat, Agus Hartoko ${ }^{1}$ \\ Program Studi Manajemen Sumberdaya Perairan, Jurusan Perikanan \\ Fakultas Perikanan dan Ilmu Kelautan, Universitas Diponegoro
}

\begin{abstract}
ABSTRAK
Dengan mengetahui area dimana ikan bisa tertangkap dalam jumlah yang besar, kegiatan penangkapan menjadi lebih efektif. Tujuan penelitian adalah mengetahui sebaran spasial cumi-cumi per-musim pada tahun 2011 hingga 2012, mengetahui sebaran spasial parameter oseanografi dan mengetahui korelasi antara parameter oseanografi dengan sebaran spasial cumi-cumi. Data yang digunakan adalah data suhu permukaan laut dan klorofil-a dari satelit MODIS Aqua dan data sekunder lapangan yaitu data hasil tangkapan cumi-cumi. Hasil dari penelitian ini menunjukkan bahwa hasil tangkapan cumi-cumi pada tahun 2011 - 2012 lebih banyak tertangkap pada musim peralihan II hingga musim barat (September-Desember) dengan nilai rata-rata hasil tangkapan setiap tahun sebesar 88 Ton dan 189 Ton. Sebaran penangkapan cumi-cumi banyak terjadi di bagian barat Laut Jawa hingga Selat Karimata. Sebaran suhu permukaan laut pada tahun 2011 musim barat lebih tinggi $\left(24,8-32,1^{\circ} \mathrm{C}\right)$ dibandingkan musim timur $\left(24,2-29,4^{\circ} \mathrm{C}\right)$, dan pada tahun 2012 juga musim barat lebih tinggi $\left(20,3-33,4^{\circ} \mathrm{C}\right)$ dibandingkan musim timur $\left(24,8-30,1^{\circ} \mathrm{C}\right)$. Sebaran Klorofil-a tahun 2011 musim timur lebih tinggi $(0,282-0,459$ $\mathrm{mg} / \mathrm{L})$ dibandingkan musim barat $(0,304-0,452 \mathrm{mg} / \mathrm{L})$, dan pada tahun 2012 juga menunjukkan sebaran klorofil-a musim timur lebih tinggi $(0,352-0,464 \mathrm{mg} / \mathrm{L})$ dibandingkan musim barat $(0,273-0,458 \mathrm{mg} / \mathrm{L})$. Analisa regresi tunggal menunjukkan nilai koefisien regresi dari distribusi klorofil-a setiap tahun $(r=0,521-0,446)$ masih memiliki hubungan dengan hasil tangkapan cumi-cumi daripada suhu permukaan laut $(\mathrm{r}=0.221-0,358)$. Analisa regresi ganda menunjukkan nilai (r) antara sebaran suhu permukaan laut dan sebaran klorofil-a pada musim timur sebesar $r=0,253$ dan pada musim barat sebesar $r=0,416$ menunjukkan bahwa musim barat memiliki hubungan yang lebih tinggi dibandingkan dengan musim timur. Hubungan tersebut karena cumi-cumi yang hidup di perairan sekitar Laut Jawa dan sekitarnya tersebar karena pengaruh arus balik musiman dari angin muson yang terjadi di antara Samudera Pasifik dan Samudera Hindia. Sebaran oseanografi hanya berpengaruh langsung terhadap beberapa spesies cumi-cumi.
\end{abstract}

Kata Kunci: Suhu Permukaan Laut, Klorofil- $a$, Data Satelit MODIS Aqua dan Sebaran Spasial Cumi-cumi

\section{ABSTRACT}

By knowing the areas where fish could be caught in large numbers, catching activities become more effective. This research is using explorative methods that aims to find out a particular social event or relationship between two or more variables. Retrieval of data using purposive sampling method. The data used was the sea surface temperature and chlorophyll-a from MODIS Aqua satellite and secondary data is data field catches of squid. The results of this research indicate that squid catches in 2011 - 2012 more were caught in the transition of monsoon II to the west monsoon (September to December) with the average value of the catch each year are 88 tons and 189 tons. Distribution of squid catching are happens on the western part of the Java Sea to the Strait Karimata. Distribution of sea surface temperature in 2011 , west monsoon are higher $\left(24.8-32.1^{\circ} \mathrm{C}\right)$ than east monsoon $\left(24.2-29.4^{\circ} \mathrm{C}\right)$, and its happened in 2012 , west monsoon are higher $\left(20,3-33,4^{\circ} \mathrm{C}\right)$ than east monsoon $\left(24,8-30,1^{\circ} \mathrm{C}\right)$. Distribution of Chlorophyll-a in east monsoon of 2011 is higher $(0.282-0.459 \mathrm{mg} / \mathrm{L})$ compared to west monsoon $(0.304-0.452 \mathrm{mg} / \mathrm{L})$, and in 2012 also shows the value of chlorophyll-a distribution high on east monsoon $(0.352-0.464 \mathrm{mg} / \mathrm{L})$ compared to the west monsoon $(0.273-0.458 \mathrm{mg} / \mathrm{L})$. Regression analysis showed a single regression coefficient of chlorophyll- $a$ distribution of each year $(\mathrm{r}=0,521-0,446)$ still have a relationship with the catch of squid compared to the sea surface temperature $(r=0.221-0,358)$. Multiple regression analysis showed values ( $\mathrm{r}$ ) between the distribution of sea surface temperature and chlorophyll-a distribution in the east monsoon are $r=0.253$ and on the west monsoon are $r=0.416$ shows that west monsoon have higher correlation than the east monsoon. The relationship happens because of the squid that live in around the Java Sea and the surrounding areas due to the influence of backflow spread of seasonal monsoon winds that occur in between the Pacific Ocean and Indian Ocean. Distribution of oceanographic parameters only directly affect a few of the several species of squid.

Keywords: Sea Surface Temperature, Chlorophyll-a, MODIS Aqua Satellite Data, Spatial Distribution of squid

*) Penulis Penanggung Jawab 


\section{Pendahuluan}

Menurut Direktorat Jendral Perikanan Tangkap (2011), Potensi sumberdaya perikanan khususnya cumicumi di Selat Karimata dan sekitarnya mencapai 2,7 ribu ton/tahun merupakan peluang bagi perikanan tangkap Indonesia agar bisa dimanfaatkan dengan baik. (Sudjoko 1988).

Cumi-cumi tergolong hewan neuritik yang sebarannya dari lapisan permukaan sampai kedalaman tertentu. Hidup bergerombol dan tertarik pada cahaya lampu (bersifat fototaksis positif). Daerah penyebarannya meliputi perairan Pasifik barat, Filipina, dan Indonesia (Hamzah dan Pramuji, 1997).

Dalam kegiatan penangkapan cumi-cumi diperlukan informasi yang efektif agar hasil tangkapan bisa mencapai hasil yang maksimal. Dengan mengetahui area dimana ikan bisa tertangkap dalam jumlah yang besar tentu saja akan menghemat biaya operasi penangkapan, waktu dan tenaga. Salah satu alternatif yang menawarkan solusi terbaik adalah mengkombinasikan kemampuan SIG dan penginderaan jauh (inderaja) kelautan. Dengan teknologi inderaja faktor-faktor lingkungan laut yang mempengaruhi distribusi, migrasi dan kelimpahan ikan dapat diperoleh secara berkala, cepat dan dengan cakupan area yang luas. Faktor lingkungan tersebut antara lain suhu permukaan laut (SST), tingkat konsentrasi klorofil-a, perbedaan tinggi permukaan laut, arah dan kecepatan arus dan tingkat produktifitas primer. Ikan dengan mobilitasnya yang tinggi akan lebih mudah dilacak disuatu area melalui teknologi ini karena ikan cenderung berkumpul pada kondisi lingkungan tertentu seperti adanya peristiwa upwelling, dinamika arus pusaran dan daerah front gradient pertemuan dua massa air yang berbeda baik itu salinitas, suhu atau klorofil- $a$ (Zainuddin, 2006).

Perubahan kondisi lingkungan berupa parameter lingkungan oseanografi berupa suhu permukaan laut (SPL) dan konsentrasi klorofil- $a$. Kajian utama dalam penelitian ini adalah menganalisa data parameter oseanografi tersebut dengan data hasil tangkapan nelayan yang berasal dari logbook milik kapal penangkapan cumi-cumi-cumi (Bouke Ami). Klorofil-a merupakan salah satu pigmen yang paling dominan terdapat pada fitoplankton dan berperan dalam proses fotosintesis. Ekosistem bahari di bumi hampir seluruhnya bergantung pada aktivitas fotosintesis tumbuhan bahari (Nybakken, 1992). Selanjutnya fitoplankton akan dimakan oleh pemakan awal (primary consumer) dan pemakan selanjutnya. Pada umumnya ikan-ikan pelagis kecil berada pada tingkat primary consumer, yaitu pemakan plankton. Tingkat kesuburan perairan (produktivitas perairan) juga dapat ditunjukkan dengan konsentrasi klorofil yang terdapat di perairan tersebut, sehingga dapat menjadi daya tarik bagi ikan-ikan pelagis yang bersifat plankton feeder.

Dengan adanya informasi hubungan parameter oseanografi dengan data sebaran spasial cumi-cumi diharapkan dapat dimanfaatkan oleh nelayan sebagai informasi tentang lokasi tangkapan berdasarkan kondisi lingkungan hidup yang baik bagi cumi-cumi-cumi di Selat Karimata dan Laut Jawa. Sehingga para nelayan dapat meningkatkan hasil tangkapannya serta lebih efisien dalam berlayar dan mengurangi konsekuensi bahan bakar yang tinggi.

\section{Tujuan dilakukannya penelitian ini adalah sebagai berikut:}

1. Mengetahui sebaran spasial Cumi-cumi (Lolligo Spp.) selama dua tahun pada tahun 2011 dan 2012 di Selat Karimata hingga Laut Jawa berdasarkan data hasil tangkapan dari PPN Kejawanan, Cirebon;

2. Mengetahui sebaran spasial suhu permukaan laut dan klorofil-a di perairan Selat Karimata hingga Laut Jawa;

3. Mengetahui korelasi antara parameter oseanografi, Suhu Permukaan Laut (SPL) dan Klorofil-a dengan sebaran spasial Cumi-cumi di Selat Karimata hingga Laut Jawa

\section{Materi dan Metode Penelitian}

\section{A. Materi Penelitian}

Materi yang digunakan dalam penelitian ini adalah data suhu permukaan laut dan klorofil-a di perairan Selat Karimata hingga Laut Jawa yang memantulkan gelombang infra merah yang selanjutnya direkam oleh sensor satelit MODIS, data hasil tangkapan Cumi-cumi per titik koordinat penangkapan yang berasal dari log book kapal penangkap Cumi-cumi (Bouke Ami), data trip penangkapan Cumi-cumi di Selat Karimata hinga Laut Jawa selama dua tahun dari tahun 2011 hingga tahun 2012. Alat yang digunakan adalah perangkat keras komputer dengan prosesor minimal Intel Core i3 untuk melakukan seluruh proses pengolahan data dan laporan penelitian, perangkat lunak yang terdiri dari Seadas 5.3 untuk transformasi format data suhu permukaan laut dan klorofil-a, ER-Mapper 7.0 untuk melakukan proses gridding (geo statistik), overlay dan layout peta persebaran suhu permukaan laut dan klorofil-a, Microsoft Excel 2003 dan SPSS 16 untuk analisis korelasi dan regresi data statistik.

\section{B. Metode Penelitian}

Metode penelitian yang digunakan yaitu metode eksploratif. Menurut Hamidi (2007), penelitian eksploratif adalah penelitian yang bertujuan untuk mencari tahu suatu kejadian sosial tertentu atau hubungan antara dua atau lebih variabel. Tujuan dari penelitian eksploratif antara lain:

1. Memuaskan rasa atau hasrat ingin tahu agar memperoleh pemahaman lebih jelas tentang peristiwa sosial yang terjadi;

2. Memperoleh tingkat kelayakan melakukan penelitian yang lebih teliti, careful study; dan

3. Mengembangkan metode-metode yang hendak digunakan dalam penelitian yang lebih teliti. 


\section{Metode Pengambilan Sampel}

Pengambilan sampel berupa data parameter oseanografis dan hasil tangkapan dilakukan dengan metode purposive sampling. Teknik ini digunakan peneliti jika peneliti memiliki pertimbangan-pertimbangan tertentu didalam pengambilan sampel atau penentuan sampel untuk tujuan tertentu (Riduan, 2008 dalam Soemitro, 2008). Pertimbangan pengambilan sampel ini didasarkan pada analisis data citra dan adanya kemudahan dalam pencapaian lokasi sampling serta jarak yang dapat dijangkau. Pengambilan data oseanografi di lakukan dengan meng-ekstrak data ASCII dari data MODIS Aqua yang kemudian dibuat peta spasialnya. Untuk data hasil tangkapan di ambil dari Pelabuhan Perikanan Nusantara Kejawanan yang kemudian akan di lakukan overlay dengan peta spasial parameter oseanografi.

\section{Analisa Sebaran Suhu Permukaan Laut dan Klorofil-a}

Data suhu permukaan laut dan klorofil-a di-download dari ocean color milik NASA-USA berupa data citra yang selanjutnya diolah menggunakan software Seadas 6.2 untuk mendapatkan data ASCII (American Standar Code for Information Interchange) yaitu data numerik yang dapat dibaca di Microsoft Excel 2007 kemudian disimpan dalam bentuk teks dokumen. Proses pengolahan ini dinamakan proses transformasi format. Pengolahan selanjutnya terdiri dari 3 tahap yaitu gridding (geo statistik), overlay dan layout yang menggunakan software Er-Mapper 7.0. Proses gridding (geo statistik) yaitu proses transformasi data pada titik koordinat menjadi layer spasial (Hartoko dan Helmi, 2004). Overlay yaitu proses penempelan atau penggabungan peta sebaran suhu permukaan laut sehingga menghasilkan output berupa peta. Layout yaitu proses memasukkan metadata agar output yang dihasilkan dapat menjadi informasi lengkap mengenai daerah sebaran spasial Cumi-cumi dan sebaran suhu permukaan laut seperti Geodetic Datum, Map Projection, jenis data, sumber data, judul, skala, dan arah mata angin.

Analisis Korelasi antara Parameter Oseanografi Suhu Permukaan Laut dan Klorofil-a dengan Hasil Tangkapan Cumi-cumi

Analisis korelasi ini dilakukan dengan melakukan regresi antara hasil tangkapan Cumi-cumi, yaitu sebagai variabel terikat (y) dengan parameter Oseanografi, suhu permukaan laut dan Klorofil-a sebagai variabel bebas $(\mathrm{x})$. Analisis ini digunakan untuk mengetahui pengaruh parameter Oseanografi terhadap koordinat titik tangkapan Cumi-cumi berdasarkan nilai koefisien korelasi (r). Menurut Hadi (2004), koefisien korelasi selalu bergerak diantara $-1 \geq \mathrm{r} \leq 1$. Koefisien korelasi antara 0 sampai +1 menunjukkan korelasi yang positif sedangkan dari - 1 sampai 0 menunjukkan korelasi yang negatif.

Tabel 1. Klasifikasi Nilai Koefisien Korelasi

\begin{tabular}{cc}
\hline Koefisien Korelasi (r) & Interpretasi \\
\hline $0,8-1$ & Tinggi \\
$0,6-0,8$ & Cukup tinggi \\
$0,4-0,6$ & Agak rendah \\
$0,2-0,4$ & Rendah \\
$0,0-0,2$ & Sangat rendah (Tak berkorelasi) \\
\hline
\end{tabular}

Sumber : Hadi (2004)

Analisis regresi dilakukan dengan menggunakan Regresi Tunggal (Single Regression) dan Regresi Ganda (Multiple Regression).

\section{Regresi tunggal (single regression)}

Regresi tunggal ini dilakukan secara bertahap (satu per satu) yaitu antara parameter Oseanografi dengan hasil tangkapan Cumi-cumi dengan tujuan untuk mengetahui parameter Oseanografi yang mungkin berpengaruh terhadap sebaran spasial Cumi-cumi. Parameter Oseanografi yang digunakan dalam penelitian ini adalah parameter suhu permukaan laut dan konsentrasi klorofil-a. Analisis ini dilakukan untuk mengetahui apakah hasil tangkapan Cumi-cumi di pengaruhi oleh setiap variable atau tidak. Regresi ini menggunakan persamaan polinomial yaitu:

$$
\mathbf{Y}=\mathbf{a}+\mathbf{b x}+\mathbf{c} \mathbf{x}^{2}
$$

dimana:

$\begin{array}{llll}\mathrm{Y} & =\text { variabel terikat (hasil tangkapan Cumi-cumi setiap titik koordinat) } & \mathrm{a} & =\text { constant } \\ \mathrm{X} & \text { = variabel bebas (parameter oseanografi) } & \mathrm{b}, \mathrm{c} & =\text { koefisien }\end{array}$

\section{Regresi ganda (Multiple regression)}

Regresi ganda atau multiple regression dilakukan dengan menggabungkan semua variabel bebas yaitu suhu permukaan laut dan konsentrasi Klorofil-a terhadap hasil tangkapan Cumi-cumi. Analisa regresi ini dilakukan untuk mengetahui apakah nilai kedua variabel bebas (suhu permukaan laut dan klorofil-a) pada titik koordinat yang sama memiliki hubungan dan dapat mempengaruhi sebaran spasial Cumi-cumi atau tidak. Regresi ganda menggunakan persamaan linier yaitu:

$$
\begin{array}{llll}
\text { dimana: } & \mathbf{Y}=\mathbf{a}+\mathbf{b}_{\mathbf{1}} \mathbf{x}_{\mathbf{1}}+\mathbf{b}_{\mathbf{2}} \mathbf{x}_{\mathbf{2}} & \\
\mathrm{Y} & =\text { Hasil tangkapan cumi-cumi di setiap titik koordinat } & \mathrm{b}_{1}, \mathrm{~b}_{2} & =\text { Koefisien regresi } \\
\mathrm{a} & \mathrm{X}_{1} & =\text { Suhu Permukaan Laut } \\
& =\text { constant } & \mathrm{X}_{2} & =\text { Klorofil-a }
\end{array}
$$




\section{Hasil dan Pembahasan \\ Kondisi Umum Lokasi Penelitian}

Selat Karimata dan Laut Jawa merupakan salah satu wilayah penangkapan cumi-cumi di Indonesia. Selat Karimata termasuk dalam Wilayah Pengelolaan Perikanan Republik Indonesia (WPP-RI) 711, sedangkan untuk Laut Jawa termasuk dalam WPP-RI 712. Selat Karimata dan Laut Jawa memiliki potensi sumber daya cumi-cumi yang besar. Cumi-cumi yang di tangkap merupakan spesies Lolligo sp. yang memang banyak terdapat di sekitar Selat Karimata dan Laut Jawa. Berdasarkan hasil wawancara jenis cumi-cumi yang di daratkan di PPN Kejawanan yaitu, Loligo duvaucelli, Loligo vulgaris, Loligo chinensi dan Loligo Edulis.

Armada penangkapan ikan di wilayah PPN Kejawanan terdiri dari 2 jenis kapal yang alat tangkapnya terdapat di masing-masing kapal yaitu kapal dengan alat tangkap gillnet dan kapal dengan alat tangkap Bouke Ami. Berdasarkan data dari PPN Kejawanan kurang lebih 85 armada penangkapan ikan yang terdaftar di PPN Kejawanan. Sebagian besar merupakan kapal dengan alat tangkap Bouke Ami, kapal-kapal tersebut mempunyai panjang berkisar antara $10 \mathrm{~m}$ sampai dengan $30 \mathrm{~m}$, dengan kapasitas penangkapan berkisar antara 20 GT hingga 97 GT.

Kapal-kapal Bouke Ami di PPN Kejawanan melakukan aktivitas penangkapan tersebar di Laut Natuna, Selat Karimata dan Laut Jawa. Jarak tempuh kapal pada waktu beroperasi berkisar antara 60-100 mil dengan waktu rata-rata berkisar antara satu hingga tiga bulan setiap kali melakukan penangkapan.

\section{Perkembangan Hasil Tangkapan Cumi-cumi}

Daerah penangkapan Cumi-cumi tersebar di Laut Natuna,Selat Karimata dan Laut Jawa dilakukan di tempat yang tidak tetap dan relatif berpindah-pindah bergantung pada musim tangkapan. Setiap kapal Bouke Ami yang melakukan aktifitas penangkapan menuju area penangkapan dengan mengandalkan pengalaman Nahkoda atau perusahaan pemilik kapal yang diduga banyak terdapat cumi-cumi. Perkembangan hasil tangkapan Cumi-cumi berdasarkan data pada tahun 2011 hingga tahun 2012 dapat dilihat pada Gambar 1 berikut:

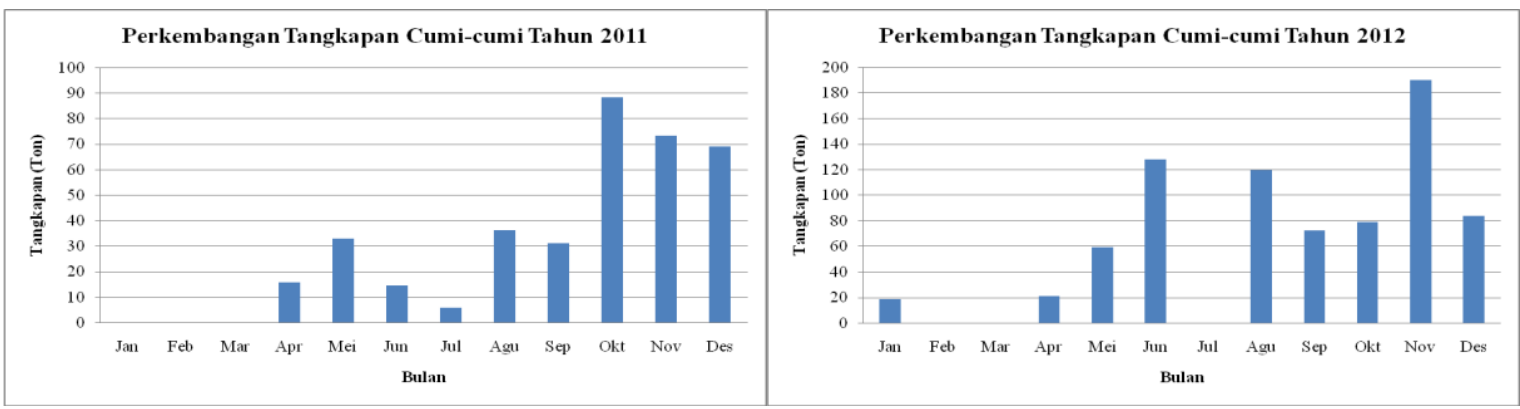

Gambar 1. Perkembangan Tangkapan Cumi-cumi Tahun 2011 dan Tahun 2012

Perkembangan Trip Penangkapan Cumi-cumi

Perkembangan trip penangkapan yang berlangsung disuatu perairan juga memiliki faktor penting yang akan mempengaruhi hasil tangkapan Cumi-cumi. Perkembangan trip penangkapan Cumi-cumi di PPN Kejawanan, Cirebon dapat dilihat pada Gambar 2 berikut:

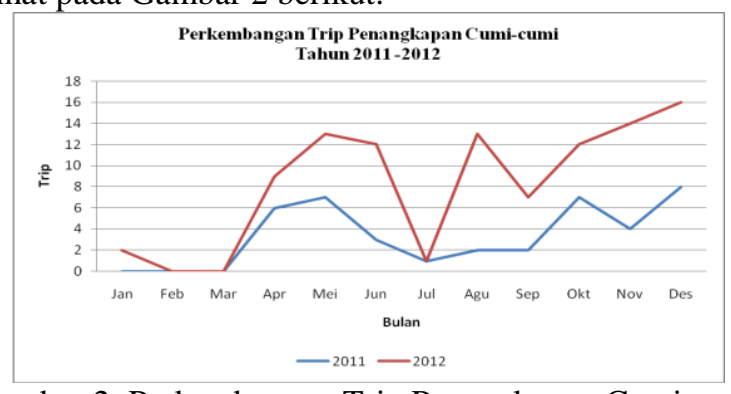

Gambar 2. Perkembangan Trip Penangkapan Cumi-cumi

\section{Sebaran Parameter Oseanografi di Selat Karimata hingga Laut Jawa}

Sebaran data parameter oseanografi ini terdiri dari sebaran suhu permukaan laut dan klorofil-a pada perairan Selat Karimata hingga Laut Jawa. Penyebaran data ini diperlukan untuk mengetahui gambaran sebaran parameter oseanografi secara umum pada perairan yang menjadi batasan penelitian dan memberikan informasi mengenai kondisi oseanografi pada setiap sebaran spasial aktifitas penangkapan Cumi-cumi. Berikut ini merupakan bahasan mengenai kondisi oseanografi selengkapnya adalah sebagai berikut:

\section{a. Suhu Permukaan Laut}

Berdasarkan dari hasil pengolahan data sebaran suhu permukaan laut di Selat Karimata hingga Laut Jawa pada setiap musim, didapatkan kisaran suhu permukaan laut pada setiap musimnya yang tersaji pada Tabel 2 berikut: 
http://ejournal-s1.undip.ac.id/index.php/maquares

Tabel 2. Kisaran Sebaran Suhu Permukaan Laut di Selat Karimata hingga Laut Jawa

\begin{tabular}{|c|c|c|}
\hline Musim & $\mathbf{2 0 1 1}$ & $\mathbf{2 0 1 2}$ \\
\hline Timur & $24,2-29,4^{\circ} \mathrm{C}$ & $24,8-30,1^{\circ} \mathrm{C}$ \\
\hline Barat & $24,8-32,1^{\circ} \mathrm{C}$ & $20,3-33,4^{\circ} \mathrm{C}$ \\
\hline
\end{tabular}

Sumber: (Pengolahan Data MODIS Aqua, 2013)

\section{b. Klorofil- $a$}

Cumi-cumi bukan pemakan Klorofil-a secara langsung, namun sebagian besar mangsa yang di cari oleh Cumi-cumi banyak yang menggunakan Klorofil-a sebagai pakan alaminya. Berdasarkan dari hasil pengolahan data sebaran Klorofil- $a$ di Selat Karimata hingga Laut Jawa pada setiap musim, didapatkan kisaran Klorofil- $a$ pada setiap musimnya yang tersaji pada Tabel 3 berikut:

Tabel 3. Kisaran Sebaran Suhu Klorofil- $a$ di Selat Karimata hingga Laut Jawa

\begin{tabular}{|c|c|c|}
\hline Musim & $\mathbf{2 0 1 1}$ & $\mathbf{2 0 1 2}$ \\
\hline Timur & $0,282-0,459 \mathrm{mg} / \mathrm{L}$ & $0,352-0,464 \mathrm{mg} / \mathrm{L}$ \\
\hline Barat & $0,304-0,452 \mathrm{mg} / \mathrm{L}$ & $0,273-0,458 \mathrm{mg} / \mathrm{L}$ \\
\hline
\end{tabular}

Sumber: (Pengolahan Data MODIS Aqua, 2013)

Analisa Korelasi antara Suhu Permukaan Laut dan Klorofil-a dengan Hasil Tangkapan Cumi-cumi

Analisa korelasi antara suhu permukaan laut dan klorofil-a dengan hasil tangkapan Cumi-cumi dilakukan dengan menggunakan regresi. Hasil analisa korelasi adalah sebagai berikut:

a. Regresi Tunggal (Single Regression)

Analisa regresi tunggal artinya melakukan analisa regresi antara suhu permukaan laut atau klorofil-a dengan hasil tangkapan Cumi-cumi.

Overlay Suhu Permukaan Laut dengan Hasil Tangkapan Cumi-cumi
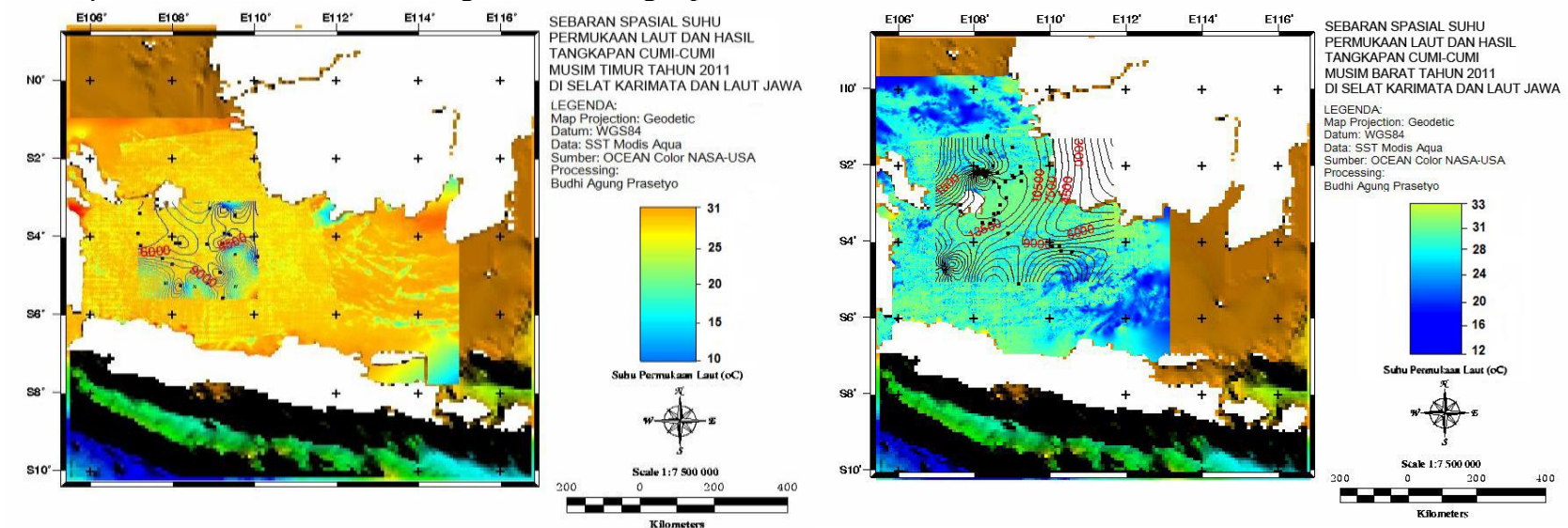

Gambar 3. Peta Overlay antara Sebaran Spasial Suhu Permukaan Laut dengan Hasil Tangkapan Cumi-cumi Tahun 2011 di Selat Karimata hingga Laut Jawa
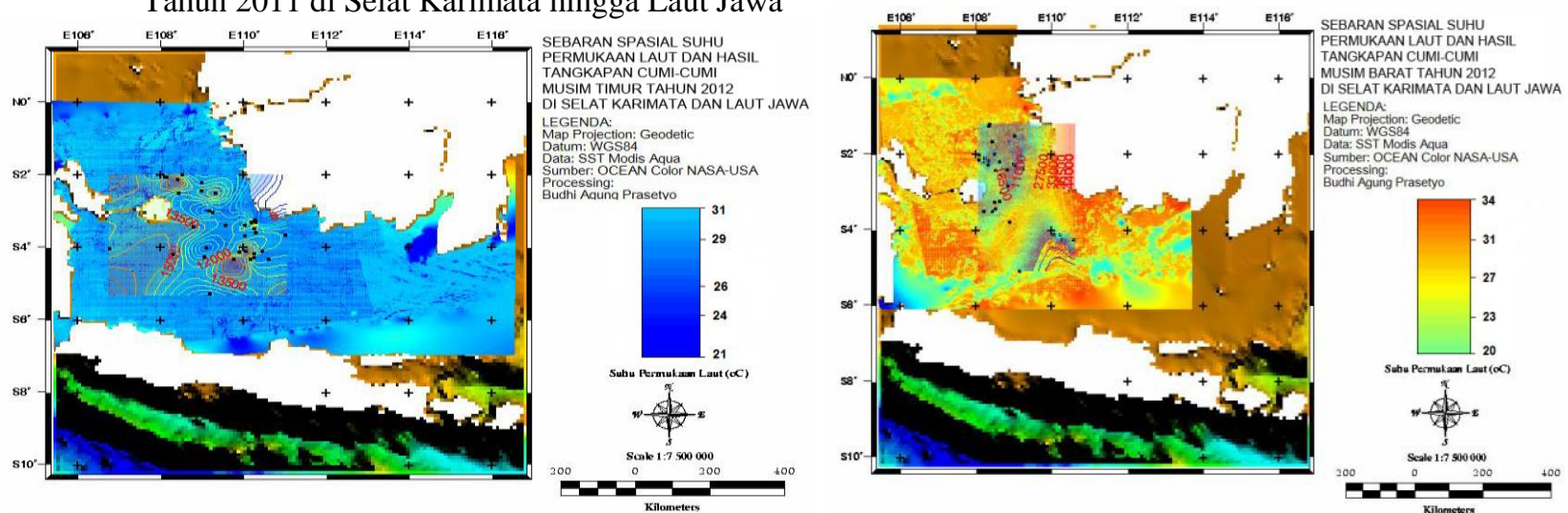

Gambar 4. Peta Overlay antara Sebaran Spasial Suhu Permukaan Laut dengan Hasil Tangkapan Cumi-cumi Tahun 2012 di Selat Karimata hingga Laut Jawa

Tabel 4. Hasil Analisa Regresi Tunggal antara SPL dan Hasil Tangkapan Cumi-cumi Tahun 2011

\begin{tabular}{ccccc}
\hline Musim & Persamaan Polinomial & $\mathbf{r}$ & $\mathbf{R}^{2}$ & Kisaran Suhu $\left({ }^{\circ} \mathbf{C}\right)$ \\
\hline Timur & $\mathbf{Y}=\mathbf{6 5 3 , 9} \mathbf{x}^{2} \mathbf{3 5 2 0 0 x}+\mathbf{4 8 0 2 0 0}$ & $\mathbf{0 . 2 2 1}$ & $\mathbf{0 , 0 4 9}$ & $\mathbf{2 4}-\mathbf{2 9}$ \\
Barat & $\mathrm{Y}=-163,9 \mathrm{x}^{2}+10040 \mathrm{x}+140900$ & 0.203 & 0,041 & $24-32$ \\
\hline
\end{tabular}


http://ejournal-s1.undip.ac.id/index.php/maquares

Tabel 5. Hasil Analisa Regresi Tunggal antara SPL dan Hasil Tangkapan Cumi-cumi Tahun 2012

\begin{tabular}{ccccc}
\hline Musim & Persamaan Polinomial & $\mathbf{r}$ & $\mathbf{R}^{2}$ & Kisaran Suhu $\left({ }^{\circ} \mathbf{C}\right)$ \\
\hline Timur & $\mathbf{Y}=\mathbf{- 2 9 6 x ^ { 2 } + 1 7 6 4 0 x - 2 4 9 4 0 0}$ & $\mathbf{0 . 3 5 8}$ & $\mathbf{0 , 1 2 8}$ & $\mathbf{2 4}-\mathbf{3 0}$ \\
Barat & $Y=-2,466 x^{2}+576,8 x-2214$ & 0.162 & 0,026 & $20-33$ \\
\hline
\end{tabular}

Sumber: (Hasil Penelitian, 2013)

Overlay Klorofil- $a$ dengan Hasil Tangkapan Cumi-cumi
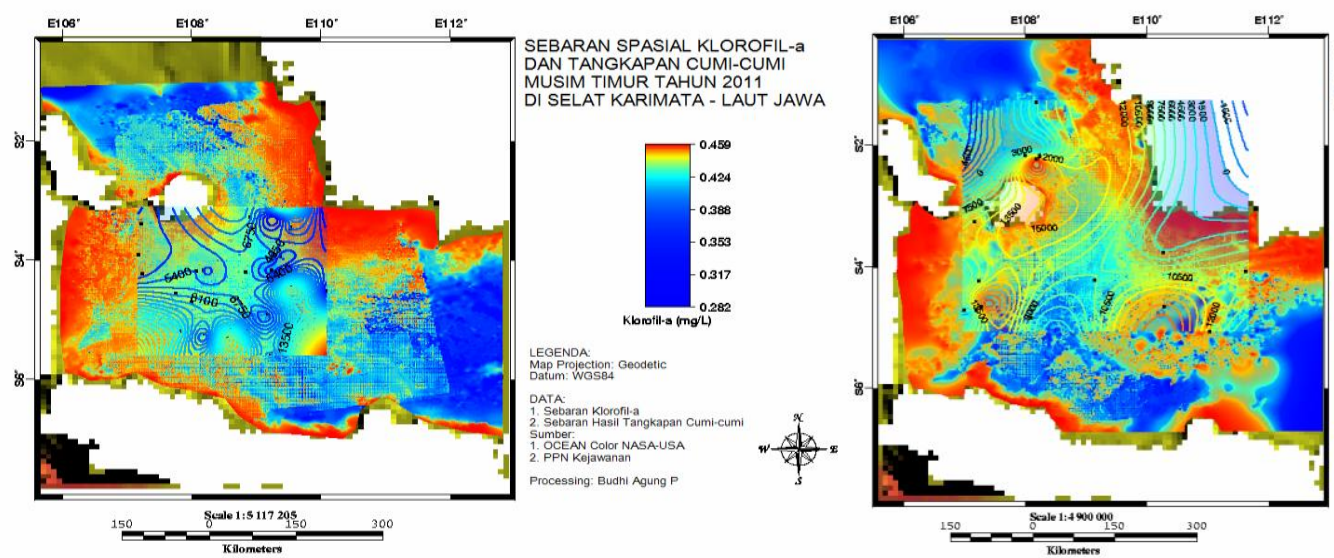

SEBARAN SPASIAL KLOROFIL-a DAN TANGKAPAN CUMI-CUM DI SELAT KARIMATA - LAUT JAWA

Gambar 5. Peta Overlay antara Sebaran Klorofil- $a$ dengan Hasil Tangkapan Cumi-cumi Tahun 2011 di Selat Karimata hingga Laut Jawa
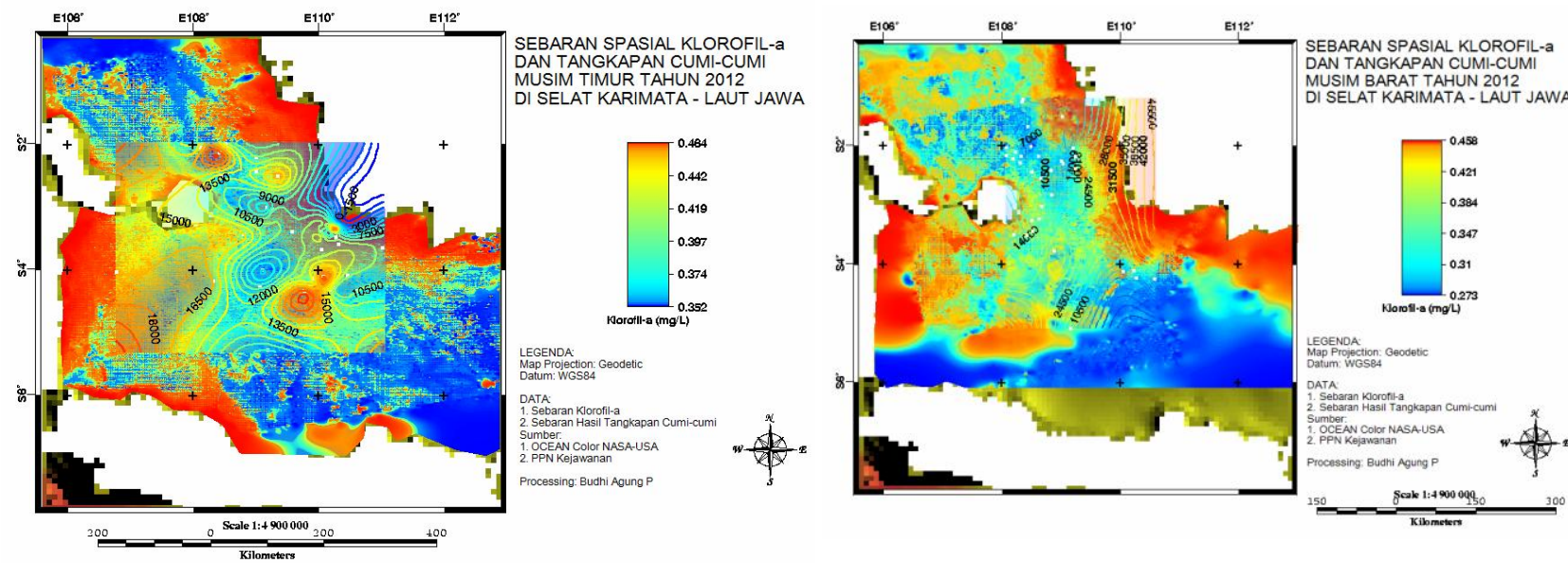

Gambar 6. Peta Overlay antara Sebaran Klorofil-a dengan Hasil Tangkapan Cumi-cumi Tahun 2012 di Selat Karimata hingga Laut Jawa

Tabel 6. Hasil Analisa Regresi Tunggal antara SPL dan Hasil Tangkapan Cumi-cumi Tahun 2011

\begin{tabular}{|c|c|c|c|c|}
\hline Musim & Persamaan Polinomial & $\mathbf{r}$ & $\mathbf{R}^{2}$ & Kisaran Klorofil-a (mg/L) \\
\hline Timur & $Y=-399100 x^{2}+328100 x-58080$ & 0.283 & 0,08 & $0,282-0,459$ \\
\hline Barat & $Y=-109800 x^{2}+115200 x-17070$ & 0.521 & 0,272 & $0,304-0,452$ \\
\hline \multicolumn{5}{|c|}{ Tabel 7. Hasil Analisa Regresi Tunggal antara SPL dan Hasil Tangkapan Cumi-cumi Tahun 2012} \\
\hline Musim & Persamaan Polinomial & $\mathbf{r}$ & $\mathbf{R}^{2}$ & Kisaran Klorofil-a (mg/L) \\
\hline Timur & $Y=-17370 x^{2}+18870 x+7854$ & 0.116 & 0,014 & $0,319-0,931$ \\
\hline Barat & $Y=22120 x^{2}+8618 x+5114$ & 0.446 & 0,199 & $0,086-0,644$ \\
\hline
\end{tabular}

Sumber: (Hasil Penelitian, 2013)

b. Regresi Ganda (Multiple Regression)

Analisa regresi ganda artinya melakukan analisa regresi antara 2 independent variable (suhu permukaan laut dan klorofil-a) dengan hasil tangkapan cumi-cumi pada musim timur dan barat. Berikut adalah hasil analisa regresi ganda antara suhu permukaan laut dan klorofil-a dengan hasil tangkapan cumi-cumi pada musim timur dan barat.

Tabel 7. Hasil Analisa Regresi Ganda antara SPL dan Klorofil- $a$ dengan Hasil Tangkapan Cumi-cumi Tahun 2011 hingga 2012

\begin{tabular}{|c|c|c|c|}
\hline Musim & Persamaan Multiple Regression & $\mathbf{r}$ & $\mathbf{R}^{2}$ \\
\hline Timur (2011-2012) & $Y=-15849,84+5036,61 x_{1}+844,39 x_{2}$ & 0,253 & 0,064 \\
\hline Barat (2011-2012) & $Y=-12079,274-13388,37 x_{1}+931,11 x_{2}$ & 0,416 & 0,173 \\
\hline
\end{tabular}

Sumber: (Hasil Penelitian, 2013) 


\section{Pembahasan}

\section{a. Perkembangan Hasil Tangkapan Cumi-cumi dengan Trip Penangkapan}

Penelitian ini difokuskan kepada hasil tangkapan utama kapal Bouke Ami yaitu Cumi-cumi (Loligo spp.) yang di daratkan di Pelabuhan Perikanan Nasional Kejawanan, Cirebon. Operasi penangkapan cumi-cumi berlangsung pada malam hari, dimana para nelayan menggunakan bantuan cahaya lampu dan bagan perahu atau biasa di sebut masyarakat nelayan di Pelabuhan Perikanan Nasional Kejawanan dengan nama Bouke Ami. Hasil operasi penangkapan tersebut berdasarkan grafik perkembangan tangkapan cumi-cumi tahun 2011 hingga tahun 2012 dapat disimpulkan bahwa hasil tangkapan cumi-cumi lebih tinggi terjadi di saat musim peralihan timur-barat. Sedangkan hasil tangkapan yang rendah terjadi pada saat peralihan musim barat-timur hingga musim timur. Penyebab tingginya hasil tangkapan cumi-cumi yang terjadi di musim peralihan timur-barat di dukung oleh beberapa faktor dan kondisi tertentu seperti kondisi gelombang laut yang tidak terlalu tinggi, suhu dan cuaca yang relatif mendukung untuk melakukan aktifitas penangkapan di musim peralihan tersebut. Menurut Hamzah dan Parmudji (1997), banyaknya jumlah tangkapan cumi-cumi pada musim peralihan timur-barat yang terjadi di sekitar bulan September, Oktober, dan November didukung oleh kondisi laut yang tenang dan kesuburan perairan yang cenderung meningkat.

Menurut data statistik Pelabuhan Perikanan Nusantara Kejawanan, aktifitas penangkapan pada tahun 2011 mencatat terdapat 28 kedatangan kapal Bouke Ami pada musim timur dengan hasil tangkapan sebanyak 224,05 Ton, sedangkan pada musim barat terdapat 23 kedatangan kapal dengan 181,64 Ton. Musim timur tahun 2011 pelabuhan mencatat ada 36 kedatangan kapal Bouke Ami dengan hasil tangkapan cumi-cumi sebesar 457,81 Ton, sedangkan pada musim barat tercatat sebanyak 32 kapal dengan hasil tangkapan 385,78 Ton. Musim timur memliki hasil tangkapan yang relatif rendah dikarenakan banyaknya kapal Bouke Ami yang tidak melakukan aktifitas penangkapan cumi-cumi di Pelabuhan Perikanan Nusantara Kejawanan, Cirebon. Berdasarkan grafik perkembangan Trip penangkapan cumi-cumi tahun 2011 hingga 2012 dari Pelabuhan Perikanan Nusantara Kejawanan, di sepanjang musim timur atau antara bulan Januari hingga Maret, hanya sedikit kapal Bouke Ami yang melakukan aktifitas penangkapan. Berdasarkan hasil survey di sepanjang musim timur atau sekitar bulan Januari hingga Maret tahun 2011 hingga tahun 2012, nelayan di PPN Kejawanan tidak melakukan aktifitas penangkapan dikarenakan faktor cuaca dan faktor teknis kapal Bouke Ami. Selain faktor cuaca dan faktor alam, jumlah trip juga mempengaruhi hasil tangkapan cumi-cumi. Dapat disimpulkan bahwa aktifitas penangkapan cumi-cumi yang di daratkan di Pelabuhan Perikanan Nusantara Kejawanan, banyak terjadi di peralihan musim timur barat karena karakteristik kondisi cuaca atau oseanografi yang mendukung sehingga mempengaruhi hasil tangkapan cumi-cumi.

Lokasi penangkapan cumi-cumi yang didaratkan di Pelabuhan Perikanan Nusantara Kejawanan pada tahun 2011 musim timur banyak tersebar di laut Jawa hingga mendekati selat karimata, dan musim barat tersebar mulai dari laut Jawa hingga Selat Karimata. Sedangkan pada tahun 2012 musim timur lokasi penangkapan cumi-cumi banyak tersebar di Selat Karimata dan sebagian Laut Jawa, dan pada musim barat sebagian besar lokasi penangkapan terdapat di Selat Karimata bagian timur dari Pulau Belitung. Data trip penangkapan cumi-cumi pada tahun 2012 lebih tinggi dua kali lipat dari tahun 2011, Berdasarkan data hasil tangkapan tahun 2012 memiliki nilai yang lebih tinggi dua kali lipat (843.59 Ton) dibandingkan dengan tahun 2011 (405,69 Ton). Terlihat jumlah trip penangkapan pada tahun 2012 yang lebih banyak hingga dua kali lipat dibandingkan dengan tahun 2011 mempengaruhi jumlah tangkapan hingga dua kali lipat. Meningkatnya jumlah trip penangkapan dapat meningkatkan jumlah hasil tangkapan cumi-cumi, namun apabila trip penangkapan tidak di dukung oleh kondisi lingkungan yang mempengaruhi kehidupan Cumicumi, hasil tangkapan dapat menurun karena stok yang berada di alam berkurang.

\section{b. Sebaran Tangkapan Cumi-cumi}

Sebaran spasial wilayah penangkapan Cumi-cumi yang di daratkan di Pelabuhan Perikanan Nusantara Kejawanan didapatkan dari log book kapal Bouke Ami, yaitu berupa titik koordinat penangkapan beserta hasil tangkapannya (ton) yang kemudian dibedakan menjadi musim timur dan musim barat. Berdasarkan data statistik Pelabuhan Perikanan Nusantara Kejawanan, wilayah yang dijadikan lokasi penangkapan oleh kapal Bouke Ami yang berdomisili di pelabuhan tersebut kebanyakan berada di Wilayah Pengelolaan Perikanan (WPP) 571 dan 572, yaitu di perairan Selat Karimata hingga dengan Laut Jawa.

Wilayah yang digunakan oleh para nahkoda kapal Bouke Ami pada setiap musim hampir sama, mereka hanya melakukan penangkapan di wilayah yang diyakini mempunyai banyak Cumi-cumi atau berdasarkan pengalaman aktifitas penangkapan sebelumnya. Mereka tidak memperhatikan kondisi oseanografis yang mempengaruhi keberadaan Cumi-cumi di suatu perairan. Beberapa nahkoda kapal Bouke Ami bahkan pernah mengakui bahwa daerah yang sebelumnya mereka yakini mempunyai banyak sumber daya Cumi-cumi, namun pada kenyataannya tidak. Beberapa bahkan tidak mendapatkan hasil tangkapan Cumi-cumi sama sekali sehingga menguras semua biaya operasional mereka. Hal inilah yang menjadi kelemahan para nahkoda kapal Bouke Ami sehingga penelitian ini dilakukan agar bisa dijadikan sumber informasi yang tepat bagi penangkapan Cumi-cumi sehingga hasil tangkapan menjadi lebih optimal.

Menurut Hartati (1998), daerah penangkapan cumi-cumi Loligonidae terdapat hampir di semua perairan di Indonesia, salah satunya Selat Malaka (Aceh, Sumatera Utara dan Riau) dan utara Jawa (Jakarta, Jawa 
Tengah dan Jawa Timur). Hal tersebut membuktikan bahwa daerah penangkapan yang ditentukan oleh para nahkoda kapal Bouke Ami akan keberadaan cumi-cumi memiliki potensi terhadap hasil tangkapan cumicumi

\section{c. Sebaran Suhu Permukaan Laut}

Berdasarkan pengolahan Data MODIS Aqua sebaran suhu permukaan laut secara spasial yang di-overlay dengan hasil tangkapan cumi-cumi pada tahun 2011 di setiap musim menunjukan kisaran sebaran suhu yang berbeda. Pada musim timur tercatat kisaran sebaran suhu di sekitar Selat Karimata hingga Laut Jawa $24,2^{\circ} \mathrm{C}$ hingga $29,4^{\circ} \mathrm{C}$, sedangkan pada musim barat tercatat kisaran suhu $24,8^{\circ} \mathrm{C}$ hingga $32,1^{\circ} \mathrm{C}$.

Sebaran suhu permukaan laut secara spasial pada tahun 2012 juga menunjukkan hal yang sama. Pada musim timur tercatat kisaran sebaran suhu $24,8^{\circ} \mathrm{C}$ hingga $30,1^{\circ} \mathrm{C}$, sedangkan pada musim barat tercatat $20,3^{\circ} \mathrm{C}$ hingga $33,4^{\circ} \mathrm{C}$. Berdasarkan pengolahan data suhu permukaan laut secara spasial tahun 2011 hingga tahun 2012 tersebut dapat disimpulkan bahwa sebaran suhu permukaan laut secara spasial di Selat Karimata hingga Laut Jawa ada musim barat lebih hangat dibandingakan dengan musim timur. Distribusi suhu permukaan laut secara spasial di Laut Jawa umumnya dipengaruhi oleh gejala musiman pada area yang lebih luas, gradien suhu secara horizontal lebih disebabkan oleh massa air yang masuk di Laut Jawa.

\section{d. Sebaran Klorofil- $a$}

Klorofil- $a$ dapat digunakan untuk menganalisis kelimpahan makanan di suatu perairan. Klorofil- $a$ merupakan pigmen hijau yang terdapat dalam fitoplankton sehingga semakin banyak jumlah fitoplankton dalam suatu perairan maka semakin tinggi kandungan klorofil- $a$ dalam perairan tersebut. Menurut Brown $e t$ al., (1989), bahwa kandungan klorofil- $a$ dapat digunakan sebagai ukuran banyaknya fitoplankton pada suatu perairan tertentu dan dapat digunakan sebagai petunjuk produktivitas perairan.

Hal tersebut berhubungan dengan proses rantai makanan yaitu dimana fitoplankton merupakan produsen primer yang menjadi makanan bagi hewan-hewan herbivora, kemudian mengundang hewan-hewan karnivora kecil yang selanjutnya daerah tersebut menjadi fishing ground dari hewan karnivora yang lebih besar di perairan seperti cumi-cumi.

Berdasarkan pengolahan data MODIS Aqua sebaran Klorofil- $a$ di Selat Karimata hingga Laut Jawa yang di-overlay dengan hasil tangkapan cumi-cumi pada tahun 2011 dapat dilihat pada musim timur berkisar antara 0,282 - 0,459 mg/L, sedangkan pada musim barat 0,304 - 0,452 mg/L. Sebaran klorofil-a di tahun 2012 pada musim timur berkisar $0,352-0,464 \mathrm{mg} / \mathrm{L}$, sedangkan pada musim barat $0,273-0,458 \mathrm{mg} / \mathrm{L}$. Dapat disimpulkan secara umum sebaran Klorofil-a pada musim timur lebih tinggi dibandingkan dengan musim barat dari kedua tahun tersebut. Selain itu sebaran klorofil-a di lokasi penangkapan cumi-cumi juga menunjukkan hal yang sama, yaitu nilai klorofil-a pada musim timur lebih tinggi daripada di musim barat. Sebaran klorofil-a di laut lebih bervariasi dibandingkan di dekat wilayah pantai. Menurut Gaol dan Sadhotomo (2007) menyatakan distribusi horizontal klorofil-a rata-rata bulanan di Laut Jawa menunjukkan konsentrasi klorofil-a lebih tinggi di perairan sekitar pantai dan semakin jauh dari pantai konsentrasi klorofil semakin kecil. Konsentrasi klorofil-a dibagian timur Laut Jawa yakni di sekitar pantai Kalimantan lebih tinggi dibandingkan dengan wilayah Laut Jawa bagian tengah. Pada musim timur penangkapan lebih banyak dilakukan di sekitar laut Jawa hingga selatan pulau Kalimantan, sedangkan pada musim barat penangkapan cumi-cumi lebih cenderung tersebar dari laut Jawa hingga Selat Karimata.

\section{e. Analisis Korelasi antara SPL dan Klorofil- $a$ dengan Hasil Tangkapan Cumi-cumi}

Informasi mengenai hubungan kisaran suhu permukanan laut dan kandungan klorofil-a terhadap Cumicumi (Loligo Spp.) dilakukan dengan analisa regresi antara suhu permukaan laut dan klorofil-a (independent) dengan hasil tangkapan Cumi-cumi (dependent) yang di bagi menjadi musim timur dan barat. Regresi ini dibedakan menjadi dua yaitu regresi tunggal (single regression) yang bertujuan untuk mengetahui pengaruh dari suhu permukaan laut atau kandungan klorofil-a pada setiap musim (timur dan barat) terhadap hasil tangkapan cumi-cumi dan regresi ganda (multiple regression) untuk mengetahui pengaruh dari hubungan suhu permukaan laut dan klorofil-a pada setiap musim (timur dan barat) terhadap hasil tangkapan cumicumi.

\section{Analisa regresi tunggal antara suhu permukaan laut dengan hasil tangkapan Cumi-cumi}

Berdasarkan hasil regresi tunggal antara suhu permukaan laut dengan hasil tangkapan cumi-cumi menunjukkan koefisien korelasi tertinggi terjadi pada musim timur tahun 2011 dan tahun 2012. Koefisien korelasi (r) pada tahun 2011 adalah sebesar 0,221 dengan kisaran suhu $24^{\circ} \mathrm{C}-29^{\circ} \mathrm{C}$ sedangkan pada tahun 2012 sebesar 0,358 dengan kisaran suhu $24^{\circ} \mathrm{C}-30^{\circ} \mathrm{C}$. Nilai koefisien korelasi ini berarti hubungan antara suhu permukaan laut dengan hasil tangkapan cumi-cumi pada musim timur tahun rendah. Koefisien determinasi $\left(\mathrm{R}^{2}\right)$ pada tahun 2011 sebesar 0,049 berarti hanya sekitar 4,9\% suhu permukaan laut mempengaruhi hasil tangkapan cumi-cumi dan 95,1\% dipengaruhi oleh faktor lain. Pada tahun 2012 koefiesien determinasi hanya sebesar 0,128 berarti hanya $12,8 \%$ suhu permukaan laut mempengaruhi hasil tangkapan cumi-cumi dan 87,2\% dipengaruhi oleh faktor lain. Hasil regresi tunggal antara suhu permukaan laut pada musim barat lebih rendah dari musim timur. Koefisien korelasi (r) musim barat tahun 2011 sebesar 0,203 dengan kisaran suhu $24^{\circ} \mathrm{C}-32^{\circ} \mathrm{C}$ sedangkan pada tahun 2012 sebesar 0,126 dengan kisaran suhu $20^{\circ} \mathrm{C}$ $-33^{\circ} \mathrm{C}$. Nilai koefisien korelasi pada musim timur tahun 2011 rendah sedangkan pada tahun 2012 sangat 
rendah. Koefisien determinasi $\left(\mathrm{R}^{2}\right)$ pada tahun 2011 sebesar 0,041 dan pada tahun 2012 sebesar 0,026, hal tersebut menunjukkan pada tahun 2011 suhu permukaan laut hanya mempengaruhi hasil tangkapan cumicumi sebesar 4,1\% sedangkan pada tahun 2012 hanya mempengaruhi sebesar 2,6\%.

Ketidakeratan atau tidak siginifikannya hubungan antara hasil tangkapan cumi-cumi dengan sebaran suhu permukaan laut disebabkan oleh pengaruh cuaca yang terjadi di bulan-bulan tertentu. Kondisi cuaca yang buruk dan tidak menentu menyebabkan aktifitas penangkapan cumi-cumi menurun sehingga hasil tangkapan yang di dapat hanya sedikit. Selain itu Cumi-cumi juga melakukan migrasi harian, dimana cumi-cumi akan mencari wilayah tertentu yang sesuai untuk keberlangsungan hidupnya. Menurut Danakusumah (1995), cumi-cumi hidup di kisaran suhu $28-32^{\circ} \mathrm{C}$ hal tersebut mempengaruhi proses metabolisme Cumi-cumi dan kelangsungan hidupnya, sehingga dapat mencerminkan dalam bentuk tingkah laku dan distribusi dari cumicumi tersebut.

\section{Analisa regresi tunggal antara klorofil-a dengan hasil tangkapan Cumi-cumi}

Berdasarkan hasil regresi tunggal antara klorofil-a dengan hasil tangkapan cumi-cumi menunjukkan koefisien korelasi tertinggi terjadi pada musim barat tahun 2011 dan tahun 2012. Koefisien korelasi (r) pada tahun 2011 adalah sebesar 0,521 dengan kisaran konsentrasi klorofil-a sebesar 0,304 - 0,452 mg/L sedangkan pada tahun 2012 sebesar 0,446 dengan kisaran konsentrasi klorofil-a sebesar 0,086 - 0,644 mg/L. Nilai koefisien korelasi ini berarti klrofil-a dengan hasil tangkapan cumi-cumi pada musim timur memliki hubungan agak rendah. Koefisien determinasi $\left(\mathrm{R}^{2}\right)$ pada tahun 2011 sebesar 0,272 berarti hanya sekitar $27,2 \%$ klorofil-a mempengaruhi hasil tangkapan cumi-cumi dan 72,8\% dipengaruhi oleh faktor lain. Pada tahun 2012 koefiesien determinasi hanya sebesar 0,199 berarti hanya 19,9\% klorofil-a mempengaruhi hasil tangkapan cumi-cumi dan $80,1 \%$ dipengaruhi oleh faktor lain. Hasil regresi tunggal antara klorofil-a pada musim barat lebih tinggi dari musim timur. Koefisien korelasi (r) musim timur tahun 2011 sebesar 0,283 dengan kisaran konsentrasi klorofil-a sebesar $0,282-0,459 \mathrm{mg} / \mathrm{L}$ sedangkan pada tahun 2012 sebesar 0,116 dengan kisaran konsentrasi klorofil-a sebesar 0,319-0,931 mg/L. Nilai koefisien korelasi pada musim timur tahun 2011 rendah sedangkan pada tahun 2012 sangat rendah. Koefisien determinasi $\left(\mathrm{R}^{2}\right)$ pada tahun 2011 sebesar 0,08 dan pada tahun 2012 sebesar 0,014, hal tersebut menunjukkan pada tahun 2011 suhu permukaan laut hanya mempengaruhi hasil tangkapan cumi-cumi sebesar 8\% sedangkan pada tahun 2012 hanya mempengaruhi sebesar $14 \%$.. Hasil ini memberikan kesimpulan bahwa kandungan klorofil-a lebih mempengaruhi hasil tangkapan Cumi-cumi daripada suhu permukaan laut, dikarenakan nilai koefisien korelasi (r) dan determinasi $\left(\mathrm{R}^{2}\right)$ pada klorofil-a lebih tinggi daripada suhu permukaan laut.

Nilai klorofil-a pada musim barat tergolong rendah, hal ini sesuai dengan pernyataan Wyrtki (1961) pada musim barat pada umumnya angin bertiup sangat kencang dengan curah hujan yang tinggi sehingga panas matahari tidak maksimal dan proses fotosintesis juga menjadi tidak maksimal. Hubungan klorofil-a dengan hasil tangkapan Cumi-cumi merupakan hubungan secara tidak langsung. Data sebaran klorofil-a di perairan Laut Jawa dan Selat Karimata digunakan untuk mengetahui tingkat kesuburan perairan tersebut. Sebaran klorofil-a tidak berpengaruh langsung dengan sebaran cumi-cumi, melainkan berpengaruh terhadap pola rantai makanan cumi-cumi itu sendiri. Karena cumi-cumi bukan hewan yang menggunakan klorofil-a secara langsung melainkan dengan menggunakan hewan lain secara perantara yang menjadi konsumen tingkat I, seperti zooplankton dan ikan-ikan pelagis kecil yang mengkonsumsi fitoplankton tersebut. Menurut Amaratunga (1983) dalam Takdir (2004) menyebutkan bahwa makanan larva cumi-cumi di alam adalah zooplankton terutama jenis-jenis cepopoda, amphipoda, mysid dan larva crustacean.

Analisa regresi ganda antara suhu permukaan laut dan kandungan klorofil-a dengan hasil tangkapan Cumicumi

\section{Analisa regresi ganda antara SPL dan Klorofil- $a$ dengan hasil tangkapan Cumi-cumi}

Berdasarkan hasil regresi ganda (multiple regression) antara sebaran suhu permukaan laut dan sebaran klorofil-a dengan sebaran tangkapan cumi-cumi pada musim timur menunjukan bahwa cumi-cumi tidak signifikan terhadap suhu permukaan laut dan klorofil-a. Sedangkan pada musim timur terlihat hubungan signifikan antara suhu permukaan laut dan klorofil-a dengan nilai signifikan di bawah nilai selang kepercayaan $(\alpha=0.05)$. Nilai korelasi (r) antara sebaran suhu permukaan laut dan sebaran klorofil-a pada musim timur sebesar $r=0,253$ dan pada musim barat sebesar $r=0,416$. Hal tersebut menunjukan bahwa pada musim barat memiliki hubungan yang lebih tinggi dibandingkan dengan musim timur. Menurut Boyle dan Paul (2005), cumi-cumi yang hidup di perairan sekitar Laut Jawa dan sekitarnya tersebar karena pengaruh arus balik musiman dari angin muson yang terjadi di antara Samudera Pasifik dan Samudera Hindia. Hanya sedikit dari beberapa spesies cumi-cumi yang berpengaruh langsung terhadap distribusi sebaran oseanografi. Hal tersebut memberikan kesimpulan bahwa sebaran spasial cumi-cumi bukan hanya bisa diketahui melalui pengukuran kedua variabel, melainkan harus mengetahui faktor-faktor lain yang sesuai dengan kelangsungan hidup cumi-cumi. Selain factor lingkungan yaitu konsentrasi klorofil-a dan SPL, ada pula faktor lain yang mempengaruhi jumlah hasil tangkapan yaitu faktor upaya penangkapan. Faktor ini terdiri jumlah trip kapal yang dilakukan, jumlah kapal yang beroperasi, alat tangkap yang digunakan,dan lain-lain, maka dari itu ada saat dimana hasil tangkapan ikan tinggi pada saat kondisi perairan kurang subur dan sebaliknya. 


\section{Kesimpulan}

Kesimpulan yang dapat diambil dari penelitian Sebaran Spasial Cumi-cumi (Loligo Spp.) dengan Variabel Suhu Permukaan Laut dan Klorofil- $a$ Data Satelit MODIS AQUA di Selat Karimata hingga Laut Jawa adalah hasil tangkapan cumi-cumi pada tahun 2011 dan 2012 lebih banyak tertangkap pada musim peralihan II hingga musim barat (September-Desember) dimana sebaran spasial penangkapan cumi-cumi banyak terjadi di bagian barat Laut Jawa hingga Selat Karimata. Sebaran suhu permukaan laut di sekitar Selat Karimata hingga Laut Jawa menunjukkan pada musim barat cenderung lebih tinggi dibandingkan dengan musim timur, dan sebaran klorofil-a pada musim timur cenderung lebih tinggi dibandingkan dengan musim barat. Hal tersebut disebabkan oleh gejala musiman masuknya massa air laut dari arah utara yang terjadi di sekitar Selat Karimata dan Laut Jawa. Korelasi antara suhu permukaan laut dan klorofil-a dengan sebaran spasial hasil tangkapan cumi-cumi menunjukkan hubungan variabel yang tidak begitu signifikan dengan nilai Koefisien korelasi (r) dan determinasi $\left(\mathrm{R}^{2}\right)$ tetapi bila dibandingkan klorofil-a masih memiliki nilai $r$ dan $\mathrm{R}^{2}$ yang lebih tinggi dibandingkan dengan suhu permukaan laut. Hal tersebut membuktikan parameter oseanografi khususnya Klorofil-a masih sedikit mempengaruhi sebaran tangkapan cumi-cumi di sekitar Selat Karimata dan Laut Jawa.

\section{Ucapan Terima Kasih}

Penulis mengucapkan terimakasih kepada Prof. Dr. Ir. Agus Hartoko, M.Sc dan Prof. Dr. Ir. Sahala Hutabarat, M.Sc atas bimbingan dan arahannya dalam penyusunan jurnal ini.

\section{Daftar Pustaka}

Boyle P. and R. Paul. 2006. Chepalopods Ecology and Fisheries. Blackwell Science Ltd, Oxford, UK.

Brown, J., A. Colling, D. Park, J. Philips, D. Rothery, and J. Wright. 1989. Ocean Circulation. The Open University. Published in Association with Pergamon Press. New York.

Danakusumah. 1995. Studi Mengenai Aspek-aspek Biologi dan Budidaya Cumi-cumi (Sepiotuehis lessonia L.) Musim Pemijahan. Pros. Seminar Kelautan Nasional 15-16 November 2005 di Jakarta.

Direktorat Jenderal Perikanan Tangkap. 2011. Peta Keragaan Perikanan Tangkap di Wilayah Pengelolaan Perikanan Republik Indonesia (WPP-RI). Kementerian Kelautan dan Perikanan, Jakarta. 68 hal.

Gaol, J. L dan B. Sadhotomo. 2007. Karakteristik dan Variabilitas Parameter Oseanografi Laut Jawa Hubungannya dengan Distribusi Hasil Tangkapan Ikan. Jurnal Penelitian Perikanan Indonesia. 13 (3): 201-211.

Hadi, S. 2004. Metodologi Research. Andi, Yogyakarta, hlm 300 - 303.

Hamidi. 2007. Metode Penelitian dan Teori Komunikasi. Press Malang, Malang.

Hamzah M.S, dan Parmudji. 1997. Pengaruh Musim Terhadap Hasil Tangkapan Cumi-cumi (Uretetuthis barchi, REHDER) Dengan Menggunakan Beberapa Alat Tangkap Di Perairan Taliabu Barat, Maluku Utara. Makalah Simposium Perikanan Indonesia II. Balitbang Sumberdaya Laut, Puslitbang Oseanografi - LIPI, Ambon.

Hartati, S.T. 1998. Fluktuasi Musiman Hasil Tangkapan Cumi-cumi (Loliginidae) di Perairan Selat Alas, NTB. [Thesis]. Program Pascasarjana, Institut Pertanian Bogor, Bogor. 64 hal.

Hartoko, A. and M. Helmi. 2004. Development of Multilayer Ecosystem Parameters Model. Journal of Coastal Development. Vol. 7, No. 3, June 2004. ISSN : 1410-5217

Nybakken, J. W. 1992. Biologi Laut: Suatu Pendekatan Ekologis. Alih bahasa oleh M. Eidman, Koesoebiono, D. G. Bengen, M. Hutomo, S. Sukardjo. Gramedia. Jakarta. 459 hal.

Sudjoko, B. 1988. Cumi-cumi (Cephalopoda Molusca) Sebagai Salah Satu Makanan dari Laut. Oseana, Jakarta, hlm $97-107$.

Takdir, M. 2004. Penetasan Telur, Pemeliharaan Larva, dan Biologi Reproduksi Cumi-cumi, Spioteuthis lessoniana LESSON. Makalah Falsafah Sains (PPS702) Sekolah Pasca Sarjana / S3 Institut Pertanian Bogor, Bogor.

Wyrtki K. 1961. Physical Oceanography of The South East Asian Waters. Naga Report. Vol. 2. Scripps Intitution of Oceanography. The University of California. La Jolla. California. $195 \mathrm{p}$.

Zainuddin, M. 2006. Aplikasi Sistem Informasi Geografis Dalam Penelitian Perikanan Dan Kelautan. Disampaikan pada Lokakarya Agenda Penelitian, COREMAP II Kab. Selayar, 9-10 September 2006. 